\title{
Linear plasmids mobilize linear but not circular chromosomes in Streptomyces: support for the 'end first' model of conjugal transfer
}

Correspondence

Carton W. Chen

cwchen@ym.edu.tw

Received 24 May 2011

Revised 26 June 2011

Accepted 27 June 2011

\author{
Hsuan-Hsuan Lee, Chin-Chen Hsu, Yen-Ling Lin and Carton W. Chen
}

\author{
Department of Life Sciences and Institute of Genome Sciences, National Yang-Ming University, \\ Taipei 112, Taiwan
}

\section{INTRODUCTION}

Conjugation is a major process leading to genetic exchange among bacteria. It is commonly mediated by conjugative plasmids (reviewed by Clewell, 1993). Besides mediating self-transfer at relatively high frequencies, conjugative plasmids also mobilize the chromosomes from donor to recipient cells at lower frequencies. In the classical model for conjugal transfer of circular plasmids in Gram-negative bacteria and many low-G + C Grampositive bacteria, transfer is initiated by nicking at a specific site on supercoiled plasmid DNA (oriT) by a relaxase (or 'nickase'), followed by rolling-circle replication (RCR; Fig. 1a). The relaxase remains covalently bound to the $5^{\prime}$ end of the nicked DNA strand, and leads the displaced strand into the recipient cell, where the DNA is circularized and converted into double-stranded form (reviewed by Byrd \& Matson, 1997). Generally about 10-20 transfer genes (tra) are clustered on these circular conjugative plasmids, and encode components of various parts of the conjugation process, including the mating pair formation complexes and relaxosomes (reviewed by Grohmann et al., 2003). Mobilization of the bacterial chromosomes is mediated by an integrated plasmid ('Hfr' chromosome) using the same RCR initiated at oriT, except that the transfer continues beyond the plasmid sequence (Fig. 1a).
The classical model is not applicable to the linear chromosomes and linear plasmids in the Gram-positive filamentous bacteria of the genus Streptomyces. These linear replicons are capped by terminal proteins (TPs) covalently bound to the $5^{\prime}$ ends of the DNA (reviewed by Chen, 2007; Kirby \& Chen, 2011). The telomere DNA sequences contain complex palindromic sequences that are important for the replication of the telomeres (Chen, 1996; Huang et al., 1998; Qin \& Cohen, 1998). Despite the linearity of the DNA, there is evidence that these Streptomyces linear replicons form supercoiled circular structures in vivo through interactions between the telomeres (Tsai et al., 2011). Interactions between the chromosomal telomere and the plasmid telomere have also been observed (Tsai et al., 2011). Moreover, Streptomyces chromosomes circularize spontaneously through fusion of the chromosomal arms at high frequencies $\left(10^{-3}-10^{-2}\right.$ per sporulation cycle) (reviewed by Chen et al., 2002).

Circular and linear plasmids are abundant in Streptomyces, and most of them are conjugative. Unfortunately, the efficient and synchronous conjugal transfer of plasmids seen in some bacteria such as Escherichia coli is not available for biochemical investigations in Streptomyces. In a typical laboratory setting, conjugation in Streptomyces occurs between multinucleoid hyphae during mixed growth of the donor and recipient cultures on solid medium over a period of several days. After that, the haploid spores are selected and scored for plasmid transfer 
(a)

(c)
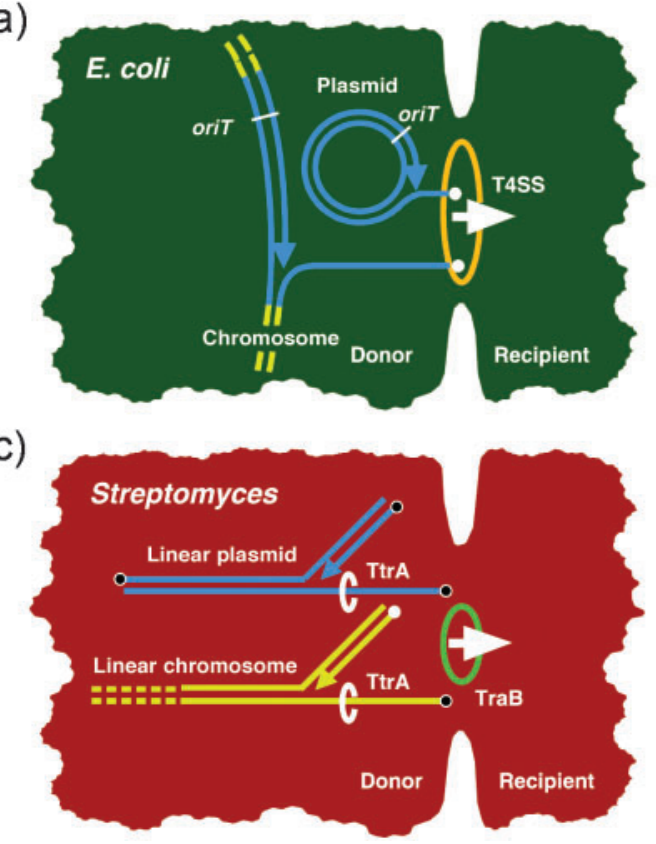

(b)

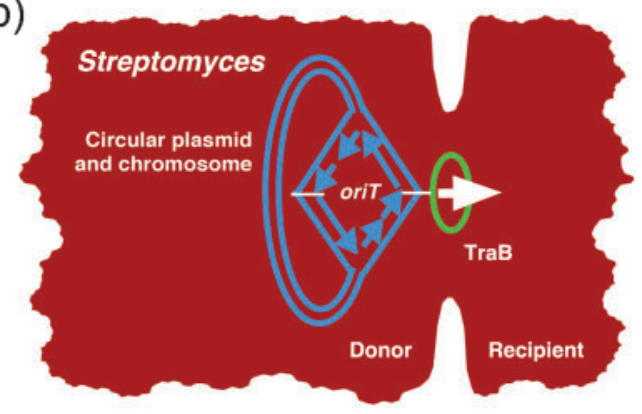

(d)

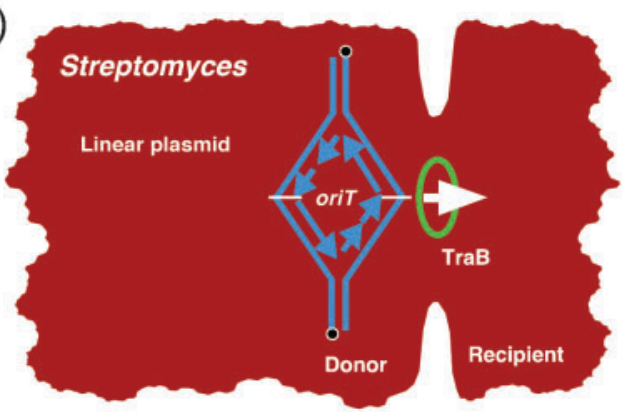

Fig. 1. Models of conjugal transfer for circular and linear plasmids in Streptomyces and other bacteria. (a) Paradigmatic model for circular plasmids and chromosomes in most bacteria (using E. coli as example). Plasmid DNA (free or integrated) is coloured in blue and the chromosomal DNA segment containing the integrated plasmid in yellow. The relaxase is represented by the white circles. The origin of transfer, oriT, is indicated by the white lines. The direction of transfer is indicated by the broad arrow. The type IV secretion system (T4SS) through which the DNA is transferred is represented by the orange circle. (b) Internal initiation model for transfer of naturally circular or artificially circularized plasmids. The leading and lagging strand synthesis in the bidirectionally progressing replication forks are represented by the single and double arrows, respectively. The TraB ring through which the DNA is transferred is represented as a green circle. (c) End first model for transfer of linear plasmids and chromosomes in Streptomyces. The linear plasmid (blue) and one end of the chromosome (yellow) are shown with covalently bound TP (black circles) at the 5' end of the transferred strand and the newly synthesized strand (blue and yellow arrows). TtrA helicase engaging in the unwinding of the telomere DNA is represented by white rings wrapping around the DNA strands. (d) Internal initiation model for transfer of linear plasmids in Streptomyces. The symbols used are the same as in (b) except for the circularity of the plasmid.

and chromosome recombination. Transfer of Streptomyces plasmids is generally very efficient (up to $100 \%$ ), and often causes a temporary inhibition of the development of the recipient mycelium, forming inhibition zones termed 'pocks', which are useful for tracking plasmid transfer (Bibb et al., 1978). In addition, progeny exhibiting recombinant parent phenotypes, reflecting recombination between donor and recipient chromosomes, emerge at frequencies of $10^{-3}-10^{-6}$ (Hopwood \& Sermonti, 1963).

Unlike the classical model, conjugal transfer of circular plasmids in Streptomyces usually requires only a single plasmid-borne traB gene (reviewed by Hopwood \& Kieser, 1993), which encodes an FtsK/SpoIIIE-type septal DNA translocase with an ATPase domain (with Walker A and B boxes), a transmembrane domain and a winged helixturn-helix (wHTH) motif (Vogelmann et al., 2011a).

The FtsK/SpoIIIE-type translocases play an important role in bacterial chromosome segregation during cell division and sporulation (reviewed by Bigot et al., 2007; Burton \&
Dubnau, 2010). They have been demonstrated in vitro to form oligomeric rings to allow DNA to pass through (Massey et al., 2006) and to translocate DNA in an ATPdependent manner (Bath et al., 2000; Pease et al., 2005). Recent studies by Burton et al. (2007) have shown that SpoIIIE forms DNA-conducting channels in the lipid bilayer and transports DNA across two bilayers during sporulation in Bacillus subtilis.

TraB of circular Streptomyces plasmid pSG5 has been shown to form foci at the hyphal tips (Reuther et al., 2006a). TraB of circular Streptomyces plasmid pSVH1 possesses no nicking activity (Reuther et al., 2006a) and forms hexamer-like rings on the membrane (Vogelmann et al., 2011b). Based on these observations, it has been proposed that Streptomyces circular plasmids are transferred as double-stranded DNA from oriT through the membrane-anchored TraB ring at the hyphal tip (Grohmann et al., 2003; Vogelmann et al., 2011a, b) (Fig. 1b). This is consistent with the demonstration by Possoz et al. (2001) that the transfer of circular Streptomyces 
plasmid pSAM2 was sensitive to the SalI restriction system present in the recipient, which digests incoming doublestranded, but not single-stranded, DNA.

Upon entry into the recipient, the plasmid requires the spread $(s p d)$ genes for spreading along the substrate and aerial mycelia and to spores. Inactivation of spd genes causes a reduction in pock sizes (Kataoka et al., 1994; Kieser et al., 1982). The spd gene products usually are small hydrophobic proteins. One spd gene product, SpdB2 of $\mathrm{pSVH} 1$, forms oligomers and interacts with TraB in vitro (Tiffert et al., 2007), leading to the proposal that TraB, SpdB2 and other spread proteins form a channel at the septal crosswalls for intrahyphal spread of the plasmid DNA. Recently, the traB and spd1 genes on linear plasmid SLP2 have been found to suppress the partitioning defect caused by deletion of the parAB operon of SLP2 (Hsu \& Chen, 2010). Apparently, plasmidless hyphae resulting from the partitioning defect may regain plasmids from plasmid-containing hyphae through intramycelial transfer and spread during colony growth.

Little is known about initiation of transfer in circular Streptomyces plasmids. Pettis \& Cohen (1994) identified a cis-acting non-coding element, clt, on pIJ101 that is required for conjugal transfer. Interestingly, clt is not required for mobilization of the host chromosome. Similar clt loci have since been found in several other circular plasmids in Streptomyces (Grohmann et al., 2003; Pettis \& Prakash, 1999; Servín-Gonzalez, 1996), Although clt may represent the origin of transfer, binding of TraB of pIJ101 to its clt was not observed (Ducote et al., 2000). On the other hand, TraB of pSVH1 binds (albeit at low affinity) to imperfect GACCCGGA octameric repeats $(c l t)$ downstream of traB (Reuther et al., 2006b; Vogelmann et al., 2011a, b).

Much less is known about the transfer mechanism of linear Streptomyces plasmids and chromosomes. The topology of the linear replicons imposes specific constraints on the site of initiation and the directionality of transfer. The classical model is not applicable for transfer of linear plasmids, because the transfer of single-stranded DNA by RCR from an internal origin cannot transport a linear plasmid DNA completely. It also cannot transfer a linear chromosome completely, and Wang et al. (1999) have previously shown that donor chromosomes are mobilized in total by linear plasmids.

An 'end first' model was proposed by Chen (1996), in which the conjugal transfer of linear Streptomyces replicons is initiated at the telomere(s) using TP-primed DNA synthesis (Fig. 1c). The model resembles the classical RCR model of transfer (Fig. 1a) in that the leading $5^{\prime}$ strand is capped by a covalently bound leader protein (relaxase in the classical model and TP in the end first model) and is displaced by a newly synthesized DNA strand. In the classical model, replication is primed by the $3^{\prime}$ free end at the nick created by the relaxase, whereas, in the end first model, replication is primed by a new TP.
TP-primed DNA synthesis is known to participate in the fill-in of the $3^{\prime}$ single-stranded gaps (of about $300 \mathrm{nt}$ ) at the telomeres ('end patching') during the replication of the linear Streptomyces replicons (reviewed by Chaconas \& Chen, 2005). In the end first model, the TP-primed DNA synthesis must extend all the way to the other end in order to transfer the complete plasmid and chromosomal DNA as single entities. Such end-to-end replication using TPs as primers is commonly used for the TP-capped linear viral genomes, typified by the Bacillus phage $\phi 29$ (reviewed by Meijer et al., 2001) and adenoviruses (reviewed by Liu et al., 2003).

The end first model is supported by the finding of a single conserved helicase-like gene, $\operatorname{ttr} A$, located in the subtelomere region of all the wholly sequenced Streptomyces chromosomes that display the typical telomere sequences. Many linear plasmids also contain one or two ttrA homologues, albeit not always terminally located. The ttrA gene has been found to be involved in the conjugal transfer of the linear plasmid SLP2 and of the linear host chromosome (Huang et al., 2003). Inactivation of ttrA on SLP2 blocked the conjugal transfer of the plasmid and the linear host chromosome. Inactivation of $t \operatorname{trA}$ on the host chromosome, however, blocked the transfer of the chromosome but not SLP2. These results suggest that, during SLP2-mediated conjugation, SLP2 transfer is necessary for chromosome transfer, and each ttrA gene may act in cis - very probably on the proximally located telomere.

Another plausible model for complete transfer of the linear replicons is bidirectional transfer from an internal origin (Fig. 1d), which is basically identical to the proposed transfer model for circular Streptomyces plasmids (Fig. 1b) except for the linearity of the substrate. We designated this the 'internal initiation' model. Because transfer is driven by bidirectional replication, the DNA enters the recipient in double-stranded form, perhaps also through the TraB ring.

In this study, we tested these models of linear replicon transfer in Streptomyces by investigating whether the telomeres of the linear plasmids and chromosomes of Streptomyces were necessary for mobilization by linear plasmids. If the end first model were correct, circularization of the linear replicons would result in a defect in transfer. Indeed, this proved to be true for the chromosomes; i.e. artificially circularized chromosomes could be mobilized by a circular plasmid, but not by a linear plasmid. On the other hand, circularization of SLP2 greatly reduced its self-transfer, but did not eliminate it completely. The remaining transfer activity was attributed to an internal initiation mechanism. The existence of the dual transfer mechanisms in SLP2 presumably reflects the acquisition of an additional transfer function during the replicon fusion that shaped this composite plasmid (Huang et al., 2003). Moreover, circularized SLP2 was segregationally unstable, which would be expected from the reduced self-transfer that would normally reinstate plasmids from 
plasmid-containing hyphae into plasmidless hyphae during growth (Hsu \& Chen, 2010).

\section{METHODS}

Bacterial strains and plasmids. The bacterial strains and plasmids used in this study are listed in Table 1. Streptomyces cultures were maintained on YM medium with the appropriate antibiotics (ATCC culture medium 196, containing, per litre: $4 \mathrm{~g}$ Difco yeast extract; $10 \mathrm{~g}$ Difco malt extract, $20 \mathrm{~g}$ Difco agar, $\mathrm{pH} 7.2$ ) at $30{ }^{\circ} \mathrm{C}$.

Recombinant DNA techniques. General recombinant DNA techniques were according to Sambrook et al. (2001). Genetic manipulations of Streptomyces were according to Kieser et al. (2000). Separation of DNA by PFGE was performed as previously described (Chen et al., 1993) in $1 \%$ agarose gel in $0.5 \times$ TBE buffer containing $25 \mu \mathrm{M}$ thiourea (Ray et al., 1995) with a $120^{\circ}$ reorientation angle and $200 \mathrm{~V}$ voltage gradient at $13{ }^{\circ} \mathrm{C}$. DNA for hybridization was labelled using DIG-Nick Translation Mix (Roche) according to the specifications supplied.

Conjugation analysis. Conjugation was performed according to Kieser et al. (2000). Approximately $10^{6}-10^{7}$ spores of each parental strain were mixed and plated on R5Cu (R2YE supplemented with $0.02 \mathrm{mM} \mathrm{CuCl}_{2}$ ) or YM agar (Kieser et al., 2000). Spores were collected after incubation at $30{ }^{\circ} \mathrm{C}$ for 7-14 days, and recombinant cultures were isolated and counted on minimal medium containing appropriate supplements and/or antibiotics. In each mating, $10^{7}-10^{10}$ spores were analysed, and 200 to over 1000 recombinants scored. The parental cultures were individually plated on the same selection medium to determine the frequencies of spontaneous mutation. The presence of conjugative plasmids was determined by (i) gel electrophoresis of total extracted DNA, (ii) thiostrepton resistance (for plasmids containing tsr), or (iii) replicating colonies onto a sensitive (plasmid-free) lawn and observing the formation of 'pocks' around the donor colonies on a recipient lawn (Kieser et al., 2000). The plasmid transfer efficiencies were calculated as the percentage of recipient spores that had received the plasmid.

Construction and isolation of circular SLP2 plasmid. Two terminal sequences of SLP2 (293-3200 bp from the left end and 12-1540 bp from the right end) were placed on two sides of the tsr gene on E. coli plasmid pCRII-TOPO (Invitrogen; containing kanamycin resistance and ampicillin resistance genes) to form a suicide plasmid, pLUS530 (see Results). pLUS530 was introduced into S. lividans 1326 by transformation. Thiostrepton-resistant and kanamycin-sensitive segregants were isolated, in which SLP2 had presumably been circularized through homologous recombination. Plasmid DNA was isolated from the candidate cultures using the procedure of Zhong et al. (2010) and analysed by PFGE, restriction and Southern hybridization. Cultures containing free circular SLP2 DNA of the correct size were used in further genetic studies.

\section{RESULTS}

\section{SLP2 replicates in Streptomyces mutants possessing artificially circularized chromosomes}

The end first transfer model for linear Streptomyces replicons (Chen, 1996) predicts that mobilization of circular donor chromosomes by linear conjugative plasmids would be defective. Unfortunately, Streptomyces strains possessing a circular chromosome and a linear plasmid were not readily available. Circularization of the Streptomyces chromosomes occurs frequently, and the resulting variants may be readily

Table 1. Bacterial strains and plasmids used in this study

\begin{tabular}{|c|c|c|}
\hline Strain/plasmid & Genotype/description & Source/reference \\
\hline \multicolumn{3}{|l|}{ S. lividans } \\
\hline 1326 & $\mathrm{SLP}_{2}{ }^{+} \mathrm{SLP}^{+}$ & Hopwood et al. (1983) \\
\hline TK64/SLP2tsr & TK64 containing SLP2tsr & Hsu \& Chen (2010) \\
\hline TK64/cSLP2tsr & TK64 containing cSLP2tsr & This study \\
\hline TK64/SCP1 & pro-2 str-6 SCP1 ${ }^{+}(=$strain 3200$)$ & Hopwood et al. (1983) \\
\hline ZX7/SLP2tsr & pro-2 str-6 rec-46 $\Delta d n d A$ SLP2tsr ${ }^{+}$ & Hsu \& Chen (2010) \\
\hline TK54 & his-2 leu-2 spc-2 & Hopwood et al. (1983) \\
\hline TK54C3 & his-2 leu-2 spc-2 $\mathrm{Cm}^{\text {s}}$; spontaneously circularized chromosome & This study \\
\hline YSC26 & pro-2 str-6 $\mathrm{Km}^{\mathrm{r}}$; artificially circularized chromosome & Lin \& Chen (1997) \\
\hline YSC26/SLP2tsr & YSC26 harbouring SLP2tsr & Lin \& Chen (1997) \\
\hline YLR5 YLR8 & $\mathrm{Km}^{\mathrm{s}}$ derivatives of YSC26; SLP2tsr ${ }^{+}$ & Lin (1998) \\
\hline M145 & $\mathrm{SCP} 1^{-} \mathrm{SCP} 2^{-}$ & Hopwood et al. (1983) \\
\hline \multicolumn{3}{|l|}{ Plasmids } \\
\hline pIJ303 & pIJ101::tsr & Kieser et al. (1982) \\
\hline pLUS530 & E. coli pCRII-TOPO plasmid containing terminal fragment of SLP2 flanking tsr gene & This study (Fig. 4a) \\
\hline SLP2tsr & SLP2 with an integrated $t s r$ gene in $\operatorname{Tn} 4811$ & Hsu \& Chen (2010) \\
\hline cSLP2tsr & Artificially circularized SLP2 containing $t s r$ & This study (Fig. 4) \\
\hline
\end{tabular}


isolated among spontaneous chloramphenicol-sensitive $\left(\mathrm{Cm}^{\mathrm{s}}\right)$ mutants (Lin et al., 1993), in which the chloramphenicol resistance gene ( $\mathrm{cmr}$ ) near the right terminus of the chromosome has been deleted (Redenbach et al., 1993). However, the $\mathrm{cmr}$ deletions generally include the more distal tap-tpg operon, which encodes a telomere-associating protein and the TP (Bao \& Cohen, 2001; Yang et al., 2002). Thus, these $\mathrm{Cm}^{\mathrm{s}}$ mutants cannot support replication of linear plasmids that lack an intact tap-tpg set, such as SLP2 (Denapaite \& Cullum, 1998; Lin, 1998). SLP2 contains a functional tpg homologue and a tpg pseudogene but no tap homologue (Fig. 2), and requires an extrinsically supplied tap gene for replication (C.-C. Yang, unpublished results).

Instead, we chose to use S. lividans strains with an artificially circularized chromosome, which was constructed previously by Lin et al. (1993), in which the two chromosomal arms were joined by a kanamycin $(\mathrm{Km})$ resistance gene (aphII) using a targeted recombination procedure. The artificially circularized chromosomes in these strains were highly unstable. Under kanamycin selection, aphII existed in tandem repeats, and, when the cultures were released from the kanamycin selection, the aphII repeats were deleted together with neighbouring sequences at frequencies approaching $100 \%$ (Lin \& Chen, 1997).

One of these strains, YSC26, under Km selection, could be transformed by SLP2tsr, an SLP2 derivative containing a thiostrepton resistance gene $t s r$ (Hsu \& Chen, 2010). In the

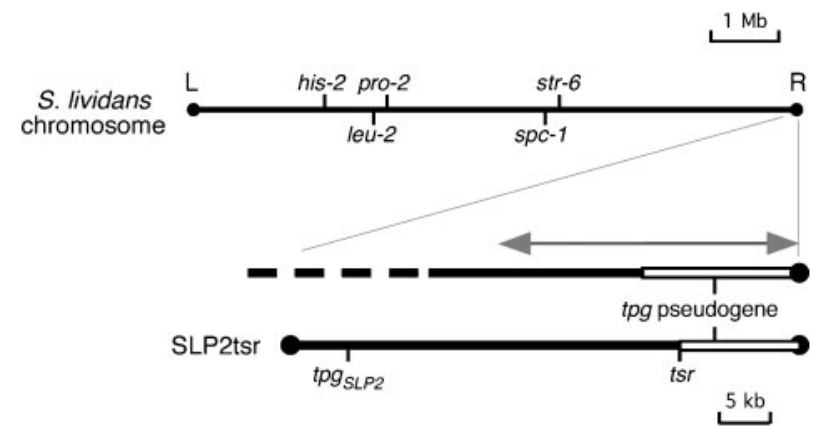

Fig. 2. Genetic maps of S. lividans. The S. lividans chromosome is represented by the horizontal line, with the TP represented by the filled circles. The designated 'left' and 'right' ends are marked by ' $L$ ' and ' $R$ '. The genetic locations of the alleles used in this study are marked. The right end of the S. lividans chromosome is enlarged below to show the $15.4 \mathrm{~kb}$ sequence (open box) that is homologous to the right end of SLP2 (Huang et al., 2003). A $3.5 \mathrm{~kb}$ stretch of the homologous region to the left of the inserted tsr was removed during the construction of SLP2tsr (shown further below) such that relocation of $t s r$ to the chromosome through homologous recombination is impossible. The terminal inverted repeat of the S. lividans chromosome is indicated by the double arrow. The tpg pseudogene on SLP2 is not functional; the tpg homologue, $t p g_{S L P 2}$ is functional, but it is not accompanied by a tap gene that is required for replication of SLP2 (C.-C. Yang, personal communication). absence of Km, YSC26/SLP2tsr segregated approximately $25 \% \mathrm{Km}^{\mathrm{s}}$ spores in a sporulation cycle (Lin, 1998), and among these $\mathrm{Km}^{\mathrm{s}}$ derivatives, approximately $38 \%$ had become thiostrepton sensitive $\left(\mathrm{Ts}^{\mathrm{s}}\right)$ and had lost SLP2tsr, while the others remained thiostrepton resistant $\left(\mathrm{Ts}^{\mathrm{r}}\right)$ and $\mathrm{Cm}^{\mathrm{r}}$ and had retained SLP2tsr.

Nine such $\mathrm{Km}^{\mathrm{s}} \mathrm{Ts}^{\mathrm{r}} \mathrm{Cm}^{\mathrm{r}}$ strains, YLR1-YLR9, were characterized with respect to the extents of deletions by hybridization of two probes, 436 and $427 \mathrm{~L}$, located at $35.7 \mathrm{~kb}$ from the right end and $34.3 \mathrm{~kb}$ from the left end of the chromosome, respectively, and adjacent to the boundaries of the $31 \mathrm{~kb}$ terminal inverted repeats (Fig. 3a). Of the nine strains, YLR5 appeared to have suffered the smallest deletions. It retained both 436 and $427 \mathrm{~L}$, indicating less than $70 \mathrm{~kb}$ of deletions. YLR8 had lost both 436 and $427 \mathrm{~L}$, and the rest had retained one of the two. Four strains, YLR5, YLR 6, YLR7 and YLR8, which maintained SLP2tsr stably (Fig. 3b), were chosen for subsequent mating experiments. They inherited the proline auxotrophic (pro-2) and streptomycin resistance (str-6) markers from their ancestral strain TK64. These genetic markers were as stable in these strains as in TK64 (reversion frequencies $<10^{-7}$ to $<10^{-9}$ ).

\section{Circular Streptomyces chromosomes are not mobilized by SLP2}

YLR5/SLP2tsr-YLR8/SLP2tsr were individually mated with a plasmidless spectinomycin-resistant $(s p c-1)$ strain of Streptomyces lividans, TK54 (Table 2, matings Ia-Id). Transfer of SLP2tsr was very efficient (approx. $50 \%$ per recipient), as previously reported. However, all attempts to select for streptomycin-resistant $\left(\mathrm{Sm}^{\mathrm{r}}\right)$ and spectinomycinresistant $\left(S p^{r}\right)$ recombinants (for genetic map see Fig. 2) failed among $10^{8}-10^{10}$ spores screened in 11 independent matings. In addition, YLR5/SLP2tsr-YLR8/SLP2tsr were individually mated with TK54C3, a Cms derivative of TK54 containing a circular chromosome isolated in this study (matings Ie-Ih). Likewise, no $\mathrm{Sm}^{\mathrm{r}} \mathrm{Sp}^{\mathrm{r}}$ recombinants were detected in any of the cases $\left(<10^{-8}\right)$.

To test whether the lack of recombination in these matings was specific for the particular markers chosen, another set of markers, $\mathrm{Sm}^{\mathrm{r}}$ and $\mathrm{Pro}^{+}$(proline prototrophy), which were more distantly separated (Fig. 2), was chosen for recombination selection. In these matings (Ia, Ib, Ie, If), YLR5 and YLR7 were the donor strains and TK54 and TK54C3 were the recipient strains. Again, no recombinant was detected $\left(<2.0 \times 10^{-7}\right.$ to $\left.<4 \times 10^{-8}\right)$. These results indicated that the absence of recombination was general, and reflected a lack of chromosome mobilization in these matings.

\section{Linear chromosomes are mobilized by linear plasmids}

The situation was different when the donor chromosomes were linear. Mating between ZX7/SLP2tsr and TK54 
(a)

YSC26

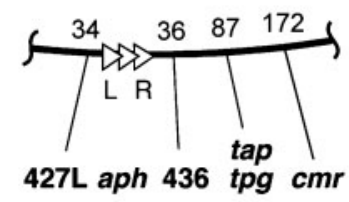

$\begin{array}{cccccc}\text { Strain } & \text { 427L aph } & \mathbf{4 3 6} & \text { tpg } & \mathrm{cmr} \\ \text { YSC26 } & + & + & + & + & + \\ \text { YLR1 } & - & - & + & + & + \\ \text { YLR2 } & + & - & - & + & + \\ \text { YLR3 } & - & - & + & + & + \\ \text { YLR4 } & - & - & + & + & + \\ \text { YLR5 } & + & - & + & + & + \\ \text { YLR6 } & - & - & + & + & + \\ \text { YLR7 } & + & - & - & + & + \\ \text { YLR8 } & - & - & - & + & + \\ \text { YLR9 } & + & - & - & + & +\end{array}$

(b)

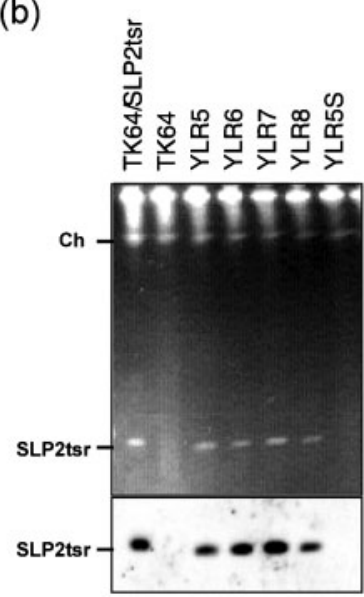

(c)

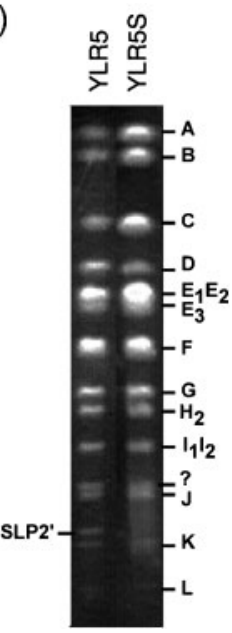

Fig. 3. S. lividans strains containing artificially circularized chromosomes. (a) Extents of deletions in the circularized chromosome. The fusion region of the circular chromosome of YSC26 is shown above. ' $L$ ' and ' $R$ ' indicate the left and right arms of the linear chromosome before circularization. The tandem amplifications containing the aphl/ gene are indicated by the open triangles. Based on the $\mathrm{Km}^{\mathrm{s}} \mathrm{Cm}^{r} \mathrm{Ts}^{r}$ phenotype, the chromosomes of YLR1-YLR9 were inferred to have lost (-) aphll $\left(\mathrm{Km}^{\mathrm{s}}\right)$, but retained $(+)$ the tap-tpg operon $\left(\mathrm{Ts}^{\mathrm{r}}\right)$ and $\mathrm{cmr}(\mathrm{Cm})$. The extents of deletions were further refined by hybridization to the $427 \mathrm{~L}$ and 436 probes (+/-). The locations of 436 and $427 \mathrm{~L}$ (flanking the $31 \mathrm{~kb}$ terminal inverted repeats), the tap-tpg operon and $\mathrm{cmr}$ are marked and their distances (in $\mathrm{kb}$ ) from the ends are indicated above. (b) Presence of SLP2tsr in YLR5YLR8. The physical presence of SLP2tsr in YLR5-YLR8 and the absence of SLP2tsr in YLR5S were confirmed by PFGE (top panel: 2-20 s ramp; run time $15 \mathrm{~h} ; 200 \mathrm{~V}$ ) and hybridization with the probe of the $3.2 \mathrm{~kb}$ Hindlll left terminal fragment of SLP2 (bottom panel). (c) Comparison of YLR5 and YLR5S genomic DNA. The genomic DNA of YLR5 and YLR5S was digested with Asel and separated by PFGE (5-10 s ramp for $160 \mathrm{~min}, 40-60 \mathrm{~s}$ ramp for $560 \mathrm{~min}, 80-100 \mathrm{~s}$ ramp for $560 \mathrm{~min}, 120-140 \mathrm{~s}$ ramp for $160 \mathrm{~min} ; 200 \mathrm{~V}$ ). The Asel fragments of $\mathrm{S}$. lividans chromosomes (A-L) and the $36 \mathrm{~kb}$ Asel fragment of SLP2tsr (marked SLP2') in YLR5 (absent in YLR5S) are indicated. The Asel site on SLP2tsr was present in the inserted tsr gene cassette. An unknown approximately $85 \mathrm{~kb}$ fragment marked '?', probably generated during the artificial circularization and rearrangements, was also found in YLR6-YLR8, which exhibited essentially the same Asel digestion patterns as YLR5.

produced $\mathrm{Sm}^{\mathrm{r}} \mathrm{Sp}^{\mathrm{r}}$ recombinants at frequencies of $4.2 \times 10^{-5}$ (Table 2, mating IIa). This was comparable with the frequencies of recombination $\left(2 \times 10^{-4}-3 \times 10^{-4}\right)$ between more distant marker pairs (his-spc or leu-spc; Fig. 2) in SPL2-mediated conjugation in S. lividans reported previously (Hopwood et al., 1983). Similar results were obtained when the recipient chromosome (TK54C3) was circular (mating IIb). In these matings, SLP2tsr was transferred at $91-100 \%$ efficiency. ZX7 was a descendant of TK64 containing a rec-46 (intraplasmid recombination deficiency; Tsai \& Chen, 1987) and a $\Delta d n d A$ (DNA sulfur modification deficiency; Zhou et al., 2005) mutation. To remove the possible effect of these mutations, TK64/ SLP2tsr was mated with TK54C3 (mating IIc). Similar recombination frequencies were observed.

Another linear plasmid SCP1 (Kinashi et al., 1987) originally found in Streptomyces coelicolor was tested. Mating of S. lividans TK64 harbouring SCP1 (Hopwood et al., 1983) with TK54 (mating IId) or its circular derivative TK54C3 (mating IIe) also produced recombinants, but at frequencies approximately one order of magnitude lower. These frequencies were in accord with those obtained by Hopwood et al. (1983).

\section{Circular chromosomes are mobilized by circular plasmids}

To test whether the failure of the circular chromosomes to be mobilized during conjugation was specific to linear plasmids, circular plasmid pIJ303, a derivative of pIJ101 (Kieser et al., 1982), was used to mediate conjugation. Firstly, YLR5 was cured of SLP2tsr by protoplasting and cold storage (Hopwood et al., 1983) and screening for $\mathrm{Ts}^{\mathrm{s}}$ derivatives. A representative, YLR5S, the genome of which was indistinguishable from that of YLR5 in AseI restriction patterns (Fig. 3c) except for the loss of SLP2 (Fig. 3b), was chosen, and pIJ303 was introduced into it by transformation. When YLR5S/pIJ303 was mated with TK54, Sm ${ }^{\mathrm{r}} \mathrm{Sp}^{\mathrm{r}}$ recombinants were recovered at frequencies of approximately $3.7 \times 10^{-6}$ (Table 2, mating IIIa).

Similarly, pIJ303 was introduced into MR04, a spontaneous $\mathrm{Cm}^{\mathrm{s}}$ mutant containing a circular chromosome with a large (approx. $700 \mathrm{~kb}$ ) deletion (Lin et al., 1993; Redenbach et al., 1993). Matings between MR04/pIJ303 and TK54 gave recombination frequencies of approximately $1.5 \times 10^{-4}$ (mating IIIb). Matings between TK64/pIJ303 and TK54C3 (mating IIIc) gave similar recombination frequencies. These 
Table 2. Mobilization of linear and circular chromosomes by naturally occurring linear and circular plasmids

Spontaneous mutation giving rise to the recombinant phenotype occurred at frequencies of $<10^{-9}$ to $<10^{-8}$ in the donor strains and $<10^{-9}$ to $10^{-7}$ in the recipient strains.

\begin{tabular}{|c|c|c|c|c|c|c|}
\hline \multirow[t]{2}{*}{ Mating* } & \multicolumn{3}{|c|}{ Topology $\dagger$ of: } & \multirow{2}{*}{$\begin{array}{c}\text { Transfer } \\
\text { frequency } \ddagger\end{array}$} & \multirow[t]{2}{*}{ Selection $\S$} & \multirow{2}{*}{$\begin{array}{l}\text { Recombination } \\
\text { frequencyll }\end{array}$} \\
\hline & Plasmid & $\begin{array}{l}\text { Donor } \\
\text { chr. }\end{array}$ & $\begin{array}{l}\text { Recip. } \\
\text { chr. }\end{array}$ & & & \\
\hline \multicolumn{7}{|c|}{ Circular chromosomes are not mobilized by linear plasmid } \\
\hline \multirow[t]{2}{*}{ Ia. YLR5/SLP2tsr $($ pro-2 str-6) $\times$ TK54 $(s p c-1)$} & $\mathrm{L}$ & $\mathrm{C}$ & $\mathrm{L}$ & $52 \pm 29(4)$ & $S m^{r} S^{r}$ & $<1.6 \times 10^{-8}(4)$ \\
\hline & & & & & $\mathrm{Pro}^{+} \mathrm{Sm}^{\mathrm{r}}$ & $<2.0 \times 10^{-7}(1)$ \\
\hline \multirow[t]{2}{*}{ Ib. YLR7/SLP2tsr (pro-2 str-6) $\times$ K54 $(s p c-1)$} & $\mathrm{L}$ & $\mathrm{C}$ & $\mathrm{L}$ & $48 \pm 32(3)$ & $S m^{r} S p^{r}$ & $<2.5 \times 10^{-8}(5)$ \\
\hline & & & & & $\mathrm{Pro}^{+} \mathrm{Sm}^{\mathrm{r}}$ & $<4.7 \times 10^{-8}(1)$ \\
\hline Ic. YLR6/SLP2tsr (pro-2 str-6) × TK54 (spc-1) & $\mathrm{L}$ & $\mathrm{C}$ & $\mathrm{L}$ & ND & $S m^{r} S p^{r}$ & $<4.4 \times 10^{-9}(1)$ \\
\hline Id. YLR8/SLP2tsr (pro-2 str-6) × TK54 $(s p c-1)$ & $\mathrm{L}$ & $\mathrm{C}$ & $\mathrm{L}$ & ND & $\mathrm{Sm}^{\mathrm{r}} \mathrm{Sp}^{\mathrm{r}}$ & $<9.9 \times 10^{-10}(1)$ \\
\hline \multirow[t]{2}{*}{ Ie. YLR5/SLP2tsr $($ pro-2 str-6) $\times$ TK54C3 $(s p c-1)$} & $\mathrm{L}$ & $\mathrm{C}$ & $\mathrm{C}$ & $80 \pm 7(1)^{\star *}$ & $S m^{r} S p^{r}$ & $<2.4 \times 10^{-8}(4)$ \\
\hline & & & & & $\mathrm{Pro}^{+} \mathrm{Sm}^{\mathrm{r}}$ & $<4.1 \times 10^{-8}(1)$ \\
\hline \multirow[t]{2}{*}{ If. YLR7/SLP2tsr (pro-2 str-6) × TK54C3 (spc-1) } & $\mathrm{L}$ & $\mathrm{C}$ & $\mathrm{C}$ & ND & $S m^{r} S p^{r}$ & $<2.3 \times 10^{-8}(5)$ \\
\hline & & & & & $\mathrm{Pro}^{+} \mathrm{Sm}^{\mathrm{r}}$ & $<3.7 \times 10^{-8}(1)$ \\
\hline Ig. YLR6/SLP2tsr $($ pro-2 str-6) $\times$ TK54C3 $(s p c-1)$ & $\mathrm{L}$ & $\mathrm{C}$ & $\mathrm{C}$ & ND & $S m^{r} S p^{r}$ & $<7.1 \times 10^{-9}(1)$ \\
\hline Ih. YLR8/SLP2tsr (pro-2 str-6) $\times$ TK54C3 $(s p c-1)$ & $\mathrm{L}$ & $\mathrm{C}$ & $\mathrm{C}$ & ND & $\mathrm{Sm}^{\mathrm{r}} \mathrm{Sp}^{\mathrm{r}}$ & $<3.1 \times 10^{-9}(1)$ \\
\hline \multicolumn{7}{|l|}{ Linear chromosomes are mobilized by linear plasmid } \\
\hline IIa. ZX7/SLP2tsr $(s t r-6) \times$ TK54 $(s p c-1)$ & $\mathrm{L}$ & $\mathrm{L}$ & $\mathrm{L}$ & $91 \pm 10(3)$ & $S m^{r} S p^{r}$ & $4.2 \pm 1.2 \times 10^{-5}(2)$ \\
\hline IIb. ZX7/SLP2tsr $(s t r-6) \times$ TK54C3 $(s p c-1)$ & $\mathrm{L}$ & $\mathrm{L}$ & $\mathrm{C}$ & $100 \pm 11(1)^{* *}$ & $S m^{r} S p^{r}$ & $4.4 \pm 3.2 \times 10^{-5}(3)$ \\
\hline IIc. TK64/SLP2tsr $(s t r-6) \times$ TK54C3 $(s p c-1)$ & $\mathrm{L}$ & $\mathrm{L}$ & $\mathrm{C}$ & $\mathrm{ND}$ & $S m^{r} S p^{r}$ & $1.7 \pm 1.9 \times 10^{-5}(4)$ \\
\hline IId. TK64/SCP1 $(s t r-6) \times$ TK54 $(s p c-1)$ & $\mathrm{L}$ & $\mathrm{L}$ & $\mathrm{L}$ & ND & $S m^{r} S p^{r}$ & $3.4 \pm 3.1 \times 10^{-6}(2)$ \\
\hline IIe. TK64/SCP1 $(s t r-6) \times$ TK54C3 $(s p c-1)$ & $\mathrm{L}$ & $\mathrm{L}$ & $\mathrm{C}$ & ND & $S m^{r} S p^{r}$ & $1.6 \pm 1.1 \times 10^{-6}(3)$ \\
\hline \multicolumn{7}{|l|}{$\begin{array}{l}\text { Circular and linear chromosomes are mobilized } \\
\text { by circular plasmid }\end{array}$} \\
\hline IIIa. YLR5S/pIJ303 $(s t r-6) \times$ TK54 $(s p c-1)$ & $\mathrm{C}$ & $\mathrm{C}$ & $\mathrm{L}$ & ND & $S m^{r} S p^{r}$ & $\begin{array}{l}3.7 \pm 0.4 \times 10^{-6} \\
(1)^{\star \star}\end{array}$ \\
\hline IIIb. MR04/pIJ303 (str-6) × TK54 $(s p c-1)$ & $\mathrm{C}$ & $\mathrm{C}$ & $\mathrm{L}$ & ND & $S m^{r} S p^{r}$ & $1.5 \pm 0.4 \times 10^{-4}(3)$ \\
\hline IIIc. TK64/pIJ303 (str-6) $\times$ TK54C3 $(s p c-1)$ & $\mathrm{C}$ & $\mathrm{L}$ & $\mathrm{C}$ & ND & $S m^{r} S p^{r}$ & $9.6 \pm 3.5 \times 10^{-5}(3)$ \\
\hline
\end{tabular}

${ }^{\star}$ Donor and recipient strains listed with only the relevant genetic markers.

$\dagger \mathrm{C}$, circular; $\mathrm{L}$, linear.

¥Frequency of plasmid transfer (\%), calculated by dividing the number of $\mathrm{Ts}^{\mathrm{r}}$ recipients by the number of total recipients scored. The mean is followed by standard deviation and the number of repeat experiments (in parentheses). In mating experiments without repeat $\left({ }^{* *}\right)$, the standard deviations were estimated by Poisson distribution based on the numbers of c.f.u. scored. ND, Not determined.

$\S$ The selection used for the calculations of recombination frequencies. $\mathrm{Sm}^{\mathrm{r}}$, streptomycin resistance; $\mathrm{Sp}^{\mathrm{r}}$, spectinomycin resistance; Pro ${ }^{+}$, proline prototrophy.

IIRecombination frequencies: mean followed by standard deviation and the number of repeat experiments (in parentheses).

results were comparable with the recombination frequencies of $10^{-3}$ between more distantly separated marker pairs ( his-spc and leu-spc) in similar matings (Kieser et al., 1982), and indicated that circular chromosomes could be mobilized by circular plasmids as efficiently as linear chromosomes could be.

\section{SLP2 is circularized by targeted recombination}

The above tests dealt with the effect of topology of the chromosomes on mobilization by plasmids. The next question was whether circularization of linear plasmids would affect their self-transfer and chromosome mobilization. To test this, we chose SLP2 for circularization using the same targeted recombination procedure as used by Lin et al. (1993). A suicide vector, pLUS530, was constructed that contains the tsr gene flanked by the left and right terminal sequences of SLP2 (Fig. 4a). S. lividans 1326 $\left(\mathrm{SLP}^{+}\right)$was transformed by this plasmid, and $\mathrm{Ts}^{\mathrm{r}}$ transformants were selected. After one round of sporulation in the absence of $\mathrm{Km}, \mathrm{Ts}^{\mathrm{r}} \mathrm{Km}^{\mathrm{s}}$ segregants were isolated and examined for circularization of SLP2.

The procedure of Zhong et al. (2010) was used to isolate the $51 \mathrm{~kb}$ circular plasmid DNA, followed by examination by PFGE, restriction and Southern hybridization. In some of the $\mathrm{Ts}^{\mathrm{r}} \mathrm{Km}^{\mathrm{s}}$ strains, SLP2 DNA appeared to have undergone rearrangements, and these strains were not 
(a)

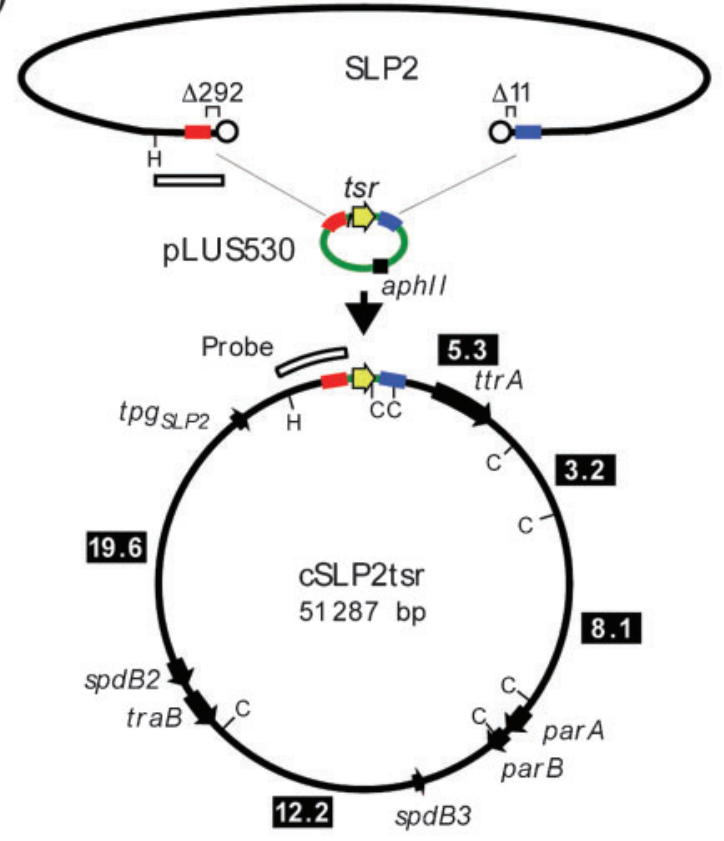

(b)

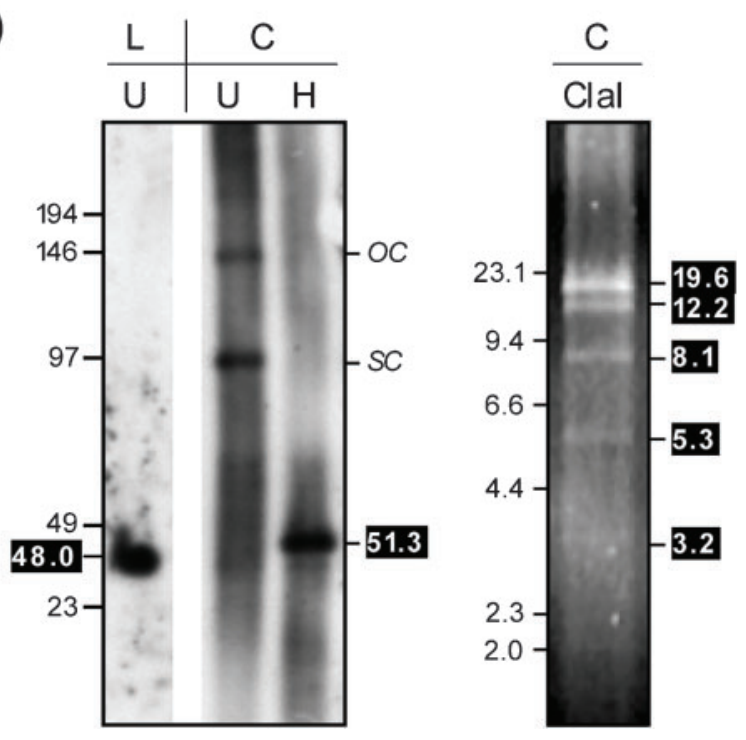

Fig. 4. Circularization of SLP2. (a) Circularization scheme. The two terminal segments at the left (red bar) and right (blue bar) arms of SLP2 (top) were placed on the suicide vector pLUS530 flanking tsr (yellow arrow), which also contained aphll (kanamycin resistance). $\Delta 292$ and $\Delta 11$ indicate the distances (in bp) between these segments and the ends of SLP2 DNA, which would be deleted during circularization. Recombination between these homologous sequences circularized SLP2 DNA (cSLP2tsr). Selected genes relevant to conjugation, partitioning, transfer and spread, as well as the Clal restriction sites (C), on cSLP2tsr are shown. The expected sizes of the five larger Clal fragments [detected in (b)] are indicated. The $3.2 \mathrm{~kb}$ Hindlll $(\mathrm{H})$ left terminal fragment of SLP2 used as the probe in Southern hybridization (below) is indicated by the open bars. (b) Physical characterization of cSLP2tsr. Left panel. cSLP2tsr DNA (C) was isolated from TK64/cSLP2tsr, digested with Hindlll $(H)$, subjected to PFGE (pulse time 3-5 s ramp; run time $24 \mathrm{~h}$ ) and hybridized with the leftterminal DNA probe. The lambda DNA size markers are indicated on the left. L, SLP2tsr DNA. U, uncut DNA. OC, open circle form of cSLP2tsr. SC, supercoiled form of cSLP2tsr. The expected sizes (in $\mathrm{kb}$ ) of the restriction fragments are shown in white numbers in the black boxes. Right panel. cSLP2tsr DNA preparation treated with Clal, separated by agarose gel electrophoresis and photographed. Southern hybridization using SLP2 DNA as probe would lead to hybridization to contaminating homologous chromosomal DNA as well as SLP2 fragments, and therefore was not used.

used. In the others, circularized SLP2 DNA could be identified in the gel as a DNA species migrating at an anomalously lower mobility than the linear counterpart (Levene \& Zimm, 1987; Sobral \& Atherly, 1989) (Fig. 4b). The size and circularity of the SLP2 DNA was confirmed by restriction digestion and Southern hybridization. This circularized SLP2 plasmid was designated cSLP2tsr. It contained the complete SLP2 sequence except for the $292 \mathrm{bp}$ and $11 \mathrm{bp}$ of the left and right ends, respectively (Fig. 4a). cSLP2tsr was unstably maintained in TK64, suffering a loss of approximately $30 \%$ in one round of a sporulation cycle in the absence of thiostrepton selection. Its linear counterpart, SLP2, was highly stable in TK64 (Hopwood et al., 1983; Hsu \& Chen, 2010).

\section{Circularized SLP2 may be transferred by a telomere-independent mechanism}

S. lividans 1326 contains another conjugative element, SLP3, which is competent for self-transfer and chromosome mobilization (Hopwood et al., 1983). To eliminate the interference of SLP3, cSLP2tsr was transferred to TK64 by transformation for subsequent conjugation experiments. TK64/cSLP2tsr and TK64/SLP2tsr were mated with TK54 and S. coelicolor M145 (Table 3, matings IVa-IVd) to examine the effect of SLP2 circularization on self-transfer and chromosome mobilization. Unlike the circularized chromosomes (Table 2, matings Ia-Ih), cSLP2tsr remained competent for transfer. However, the transfer frequency was reduced 50 -fold ( $2 \%$ versus $100 \%$ and $1.5 \%$ versus $75 \%$, respectively) in both matings. The transfer of cSLP2tsr and SLP2tsr plasmids in these matings was confirmed in selected samples by PFGE and Southern hybridization (data not shown). The decrease in cSLP2tsr self-transfer supports the involvement of the end first mechanism in SLP2 transfer; yet the residual transfer also indicated the presence of a telomere-independent mechanism for SLP2 transfer, which accounted for about $2 \%$ of the transfer events.

Recombination frequencies in these matings were also similarly affected by the circularization of SLP2: they were 
Table 3. Effect of circularization of SLP2 on self-transfer and chromosome mobilization

All the footnotes are as the same as in Table 2. Spontaneous mutation giving rise to the recombinant phenotype occurred at frequencies of $10^{-9}$ to $10^{-8}$ in the donor strains and $<10^{-9}$ to $10^{-7}$ in the recipient strains.

\begin{tabular}{|c|c|c|c|c|c|c|}
\hline \multirow[t]{2}{*}{ Mating* } & \multicolumn{3}{|c|}{ Topology $\dagger$ of: } & \multirow{2}{*}{$\begin{array}{c}\text { Transfer } \\
\text { frequency } \ddagger\end{array}$} & \multirow[t]{2}{*}{ Selection $§$} & \multirow{2}{*}{$\begin{array}{l}\text { Recombination } \\
\text { frequencyll }\end{array}$} \\
\hline & Plasmid & $\begin{array}{c}\text { Donor } \\
\text { chr. }\end{array}$ & $\begin{array}{l}\text { Recip. } \\
\text { chr. }\end{array}$ & & & \\
\hline IVa. TK64/SLP2tsr (pro-2 str-6) × TK54 $(s p c-1)$ & $\mathrm{L}$ & $\mathrm{L}$ & $\mathrm{L}$ & $107.6 \pm 23.5(5)$ & $\mathrm{Sm}^{\mathrm{r}} \mathrm{Sp}^{\mathrm{r}}$ & $3.4 \pm 4.8 \times 10^{-6}(5)$ \\
\hline IVb. TK64/cSLP2tsr (pro-2 str-6) × TK54 (spc-1) & $\mathrm{C}$ & $\mathrm{L}$ & $\mathrm{L}$ & $1.9 \pm 1.2(5)$ & $S m^{r} S p^{r}$ & $3.1 \pm 4.0 \times 10^{-7}(5)$ \\
\hline IVc. TK64/SLP2tsr (pro-2 str-6) × M145 & $\mathrm{L}$ & $\mathrm{L}$ & $\mathrm{L}$ & $74.8 \pm 7.5^{* *}(1)$ & $\mathrm{Pro}^{+} \mathrm{Sm}^{\mathrm{r}}$ & $1.3 \pm 0.2 \times 10^{-6}(2)$ \\
\hline IVd. TK64/cSLP2tsr (pro-2 str-6) $\times$ M145 & $\mathrm{C}$ & $\mathrm{L}$ & $\mathrm{L}$ & $1.5 \pm 0.6(6)$ & Pro $^{+} \mathrm{Sm}^{\mathrm{r}}$ & $<6 \times 10^{-8}-<2 \times 10^{-7}(6)$ \\
\hline
\end{tabular}

reduced from $3.4 \times 10^{-6}$ to $3.1 \times 10^{-7}$ in the TK64 to TK54 transfer, and from $1.3 \times 10^{-6}$ to non-detectable $\left(<6 \times 10^{-8}\right.$ to $<2 \times 10^{-7}$ ) in the TK64 to M145 transfer. This also supported the end first mechanism for the transfer of linear chromosomes.

\section{DISCUSSION}

\section{Retro-transfer is unlikely}

Previous genetic studies indicate that recombination during Streptomyces mating occurs via merozygotic intermediates, which is similar to other bacterial systems (Hopwood et al., 1984). In their comparative analysis, Wang et al. (1999) noticed that the composition of the merozygotes depended on the topology of the conjugative plasmids. In circular-plasmid-mediated conjugation, the merozygotes contain a partial chromosome from the donor and a complete chromosome from the recipient (as in other bacteria), whereas in linear-plasmid-mediated conjugation, the situation is reversed - the merozygotes consist of a complete chromosome from the donor and an incomplete chromosome from the recipient. Two alternative possibilities were raised to account for the latter: (i) the linear-plasmid-driven transfer exerted an unknown destructive effect on the integrity of the recipient chromosomes; and (ii) there was efficient retro-transfer of a partial chromosome from the recipient to the donor where recombination takes place.

This uncertainty may be addressed by considering the results of the matings between a donor containing a circular chromosome plus a linear plasmid (SLP2tsr) with a recipient containing a linear chromosome (Table 2, matings Ia and Ib). In these matings, the plasmid was transferred at about $50 \%$ efficiency, but no recombination was detected. Apparently, acquisition of the plasmids in the recipients had not promoted retro-transfer at a significant level. Thus, the possibility of retro-transfer may be discounted in our assessment of (at least) linear-plasmiddriven conjugal transfer.

\section{Chromosome mobilization by integrated linear plasmids is unlikely}

We do not know how Streptomyces chromosomes are mobilized by linear plasmids, and it might be argued that they are mobilized via integration of the plasmid DNA and that the failure of the circular chromosomes to be mobilized is due to some terminal sequences, which were removed during circularization, containing homologous sequences necessary for recombination with the linear plasmids.

Indeed the deletions in the artificially circularized chromosomes in YLR5-YLR8 do include the $15.4 \mathrm{~kb}$ terminal sequence of the $S$. lividans chromosomes shared by the right end of SLP2 (Fig. 2) (Lin, 1998). One may argue that the $15.4 \mathrm{~kb}$ homologous sequence is required for integration of SLP2. However, homologous recombination between two linear molecules cannot form a single cointegrate. In the case of SLP2 and the S. lividans chromosomes, homologous recombination between the terminal homologous sequences would be futile, giving rise to two products with unchanged sequences.

The main obstacle for the integration model is how a linear plasmid may integrate into (or excise from) a linear chromosome without any sequence loss. In the NF (Hopwood et al., 1969) and NF-like (Vivian \& Hopwood, 1973) strains of S. coelicolor, the integrated SCP1 mobilizes the chromosome efficiently, but they are truncated at both ends (Hanafusa \& Kinashi, 1992; Kinashi et al., 1992; Yamasaki et al., 2001). A circular-chromosome-mobilizing genetic element, pSAM2 of Streptomyces ambofaciens, is normally integrated at a specific site of the chromosome (Boccard et al., 1989), but it is excised and replicates as a circular molecule before transfer to the recipient, where it is again integrated into the chromosome (Possoz et al., 2001). Other than these, no integration of conjugative plasmids (linear or circular) has ever been detected in the donor or recipient chromosomes in matings driven by free plasmids in Streptomyces.

Moreover, no specialized enzymic system for integration and excision (such as those employed by integrative linear replicons like lambdoid phages, retroviruses and 
retrotransposons) is found in SLP2, making it unlikely that it may mobilize the chromosomes by integration. We conclude that the inability of these linear plasmids to mobilize a circular chromosome is not due to a defect in plasmid integration but due to the absence of functional telomeres on the chromosomes.

\section{Linear plasmids mobilize Streptomyces chromosomes from the ends}

In these circumstances, the end first mechanism remains the favoured model to account for the deficiencies in mobilization of circularized Streptomyces chromosomes. In this study, this has been demonstrated exhaustively in four different donor strains. No mobilization of circular donor chromosomes was ever detected $\left(<10^{-7}\right.$ to $\left.<10^{-9}\right)$, while SLP2tsr transfer was normal and efficient (at approximately $50 \%$ ). The topology of the donor chromosomes appears to be the crucial element, as all the three other topological combinations of the donor genome - (i) linear plasmid + linear chromosome, (ii) circular plasmid + linear chromosome and (iii) circular plasmid + circular chromosome - allowed detectable transfer of the donor chromosome. The last combination is most noteworthy in that the same circular chromosomes that were not mobilized by linear plasmids could be readily mobilized by a circular plasmid (Table 2 , matings IIIa and Ia). This implies a basic mechanistic difference in chromosome mobilization mediated by a linear plasmid and by a circular plasmid in Streptomyces. Presumably the linear plasmid mobilizes the chromosome from its telomeres by the same end first mechanism for selftransfer and the circular plasmid mobilizes the chromosome by the internal initiation mechanism.

The end first model is supported by the involvement of the terminally located putative helicase gene ttrA in linearplasmid-mediated conjugal transfer. The defects in plasmid and chromosome transfer caused by $\operatorname{ttrA}$ mutations were initially observed in S. lividans-to-S. coelicolor interspecific transfers (Huang et al., 2003). Later, two reports (Wang \& Pettis, 2010; Xu et al., 2006) failed to observe the same effect of ttrA deletions on plasmid transfer from S. lividans to S. lividans. The discrepancy could be attributed to the difference in the choices of mating partners: while the donor strains were all S. lividans, the recipient was S. coelicolor in the first case and S. lividans in the other two cases. This suspicion was supported by the recent observations that $\operatorname{tr} A$ deletions in SCP1 also blocked plasmid transfer from $S$. lividans to $S$. coelicolor, but not from S. lividans to S. lividans (C.-H. Huang, personal communication). At present, the possible underlying mechanism for the discrepancy may only be speculated upon.

\section{Linear plasmids are transferred by two mechanisms}

Circularization of SLP2 reduced plasmid transfer 50-fold from TK64 to TK54 and to M145. A smaller reduction in plasmid transfer was observed in a circularized partial SLP2 plasmid pQC588 (spanning ORFs SLP2.4-SLP2.23; Xu et al., 2006). While these observations support the end first mechanism (Fig. 1c), the remaining transfer must represent a telomere-independent transfer mechanism, i.e. the internal initiation mechanism (Fig. 1d). As discussed in the Introduction, such an internal initiation mechanism must replicate bidirectionally in order to transfer the complete plasmid and for the DNA to enter the recipient in a double-stranded form.

In these matings, the end first mechanism appeared to contribute about $98 \%$ of the observed transfer, whereas the internal initiation mechanism contributed $2 \%$. It is not clear how these two mechanisms interact. However, it is clear that both depend on $t r a B$, because no self-transfer of SLP2 can be detected $\left(<10^{-7}\right)$ if $t r a B$ is deleted (Hsu \& Chen, 2010). Presumably, DNA mobilized by either mechanism is pumped through the TraB ring (Fig. 1c, d). If the TraB ring only transports double-stranded DNA, the TP-led DNA strand must be converted into duplex form in the donor prior to transfer.

Is the existence of such a dual transfer mechanism in SLP2 common among linear plasmids in Streptomyces? The answer to this question must await further investigation. It is possible that this is a special case for SLP2 and possibly some other large linear plasmids. The two transfer activities may represent independent functions inherited from two ancestral plasmids (a circular and a linear one) that now make up SLP2. Previous analysis of the SLP2 sequence has revealed: (i) apparent exchange with the host chromosomal telomeres; (ii) two dissimilar telomere sequences; and (iii) a tpg pseudogene (Fig. 2) and pseudo-telomere sequences. All these indicate that SLP2 is a composite plasmid that has evolved from several rounds of recombination involving at least three replicons (Huang et al., 2003). It is likely that one of the ancestral replicons was a circular plasmid, which brought in the internal initiation transfer function. This additional function would complement the end first mechanism and provide a selective advantage in helping the spread of SLP2 in nature, particularly when it has suffered accidental circularization. Recently, a $2 \mathrm{~kb}$ internal cisacting element for conjugal transfer was located in SLP2 (Hsueh, 2009), which may be involved in the internal initiation mechanism. This sequence spans from the $3^{\prime}$ terminus of $\operatorname{traB}$ to the $5^{\prime}$ terminus of the downstream putative transglycosylase gene and contains many short repeats.

Similarly, an internal cis-acting element involved in conjugal transfer has also been identified in SCP1 (C.-H. Huang, personal communication). That SCP1 may also contain an internal initiation mechanism can be inferred from the conjugal behaviour of the chromosome in the NF strain of S. coelicolor. Transfer of the NF chromosome exhibits a distinct bidirectional polarity from the integrated SCP1 (100\% transfer) to more distant markers on both 
sides (Hopwood et al., 1969). This suggests a bidirectional transfer initiated internally from the integrated SCP1. The $350 \mathrm{~kb}$ sequence of SCP1 also reveals a mosaic nature (Bentley et al., 2004).

\section{The instability of cSLP2tsr may reflect its defect in conjugal transfer}

Despite its relatively low copy number (about two per chromosome; Chen et al., 1993), SLP2 is stably maintained (Hopwood et al., 1983; Hsu \& Chen, 2010). The results in this study show that cSLP2tsr was lost at high frequencies during a sporulation cycle. Likewise, plasmid pQC588, a circularized partial SLP2 (spanning ORF SLP2.4 to approximately SLP2.23) with a reduction in self-transfer efficiency (Xu et al., 2006) also exhibits similar segregational instability (Z. Qin, personal communication). The segregational instability in these circularized SLP2 plasmids may be (at least partially) accounted for by the deficiency in self-transfer. It has been shown previously that traB-mediated transfer was involved in reintroduction of SLP2 from plasmid-containing hyphal segments to other segments that had suffered plasmid loss during colony growth (Hsu \& Chen, 2010). Another non-exclusive possibility is that the telomeres of the plasmids may play a role in post-replicational segregation - perhaps through interaction between the plasmid telomeres and the chromosomal telomeres as previously proposed by Tsai et al. (2011).

\section{Terminal proteins are crucial to end first transfer}

In the end first model, TP plays the crucial dual roles of primer for replication initiation and leader for the covalently attached DNA to enter the recipient (Fig. 1c). In the classical model, transfer of the relaxase-capped DNA employs a type IV protein secretion system (T4SS; reviewed by Cascales \& Christie, 2003) and it is possible that relaxase protein itself is transferred and the attached DNA is transferred passively. In the end first model, TP might also be transported by a protein secretion system, with the DNA following passively.

Moreover, in vitro TPs (both archetypal Tpg on most Streptomyces chromosomes and plasmids and atypical Tpc on SCP1) can also lead the attached DNA to the nuclei of human (Tsai et al., 2008) and plant cells (Lai, 2010) using their nuclear localization signals (NLSs). In Ti-plasmid-mediated conjugation between Agrobacterium tumefaciens and plant cells, the Ti-plasmidencoded relaxase VirD2 also contains an NLS, and doubles as a protein that leads Ti-DNA into the plant cell as well as a protein that targets T-DNA into the plant nucleus (Tinland et al., 1992). This intriguing comparison hints at possible TP-mediated inter-kingdom conjugal transfers from Streptomyces to certain eukaryotes in the soil.

\section{ACKNOWLEDGEMENTS}

We thank Drs David A. Hopwood, Ralph Kirby and Hsiu-Hui Tsai for critical reading of the manuscript. This research was supported by research grants from the National Science Council (NSC98-2311-B010-004, NSC99-2321-B-010-006) and the Ministry of Education (Aim for the Top University Plan), R.O.C.

\section{REFERENCES}

Bao, K. \& Cohen, S. N. (2001). Terminal proteins essential for the replication of linear plasmids and chromosomes in Streptomyces. Genes Dev 15, 1518-1527.

Bath, J., Wu, L. J., Errington, J. \& Wang, J. C. (2000). Role of Bacillus subtilis SpoIIIE in DNA transport across the mother cell-prespore division septum. Science 290, 995-997.

Bentley, S. D., Brown, S., Murphy, L. D., Harris, D. E., Quail, M. A., Parkhill, J., Barrell, B. G., McCormick, J. R., Santamaria, R. I. \& other authors (2004). SCP1, a 356,023 bp linear plasmid adapted to the ecology and developmental biology of its host, Streptomyces coelicolor A3(2). Mol Microbiol 51, 1615-1628.

Bibb, M. J., Ward, J. M. \& Hopwood, D. A. (1978). Transformation of plasmid DNA into Streptomyces at high frequency. Nature 274, 398-400.

Bigot, S., Sivanathan, V., Possoz, C., Barre, F. X. \& Cornet, F. (2007). FtsK, a literate chromosome segregation machine. Mol Microbiol 64, 1434-1441.

Boccard, F., Smokvina, T., Pernodet, J. L., Friedmann, A. \& Guérineau, M. (1989). The integrated conjugative plasmid pSAM2 of Streptomyces ambofaciens is related to temperate bacteriophages. EMBO J 8, 973-980.

Burton, B. \& Dubnau, D. (2010). Membrane-associated DNA transport machines. Cold Spring Harb Perspect Biol 2, a000406.

Burton, B. M., Marquis, K. A., Sullivan, N. L., Rapoport, T. A. \& Rudner, D. Z. (2007). The ATPase SpoIIIE transports DNA across fused septal membranes during sporulation in Bacillus subtilis. Cell 131, 1301-1312.

Byrd, D. R. \& Matson, S. W. (1997). Nicking by transesterification: the reaction catalysed by a relaxase. Mol Microbiol 25, 1011-1022.

Cascales, E. \& Christie, P. J. (2003). The versatile bacterial type IV secretion systems. Nat Rev Microbiol 1, 137-149.

Chaconas, G. \& Chen, C. W. (2005). Linear chromosomes in bacteria: no longer going around in circles. In The Bacterial Chromosome, pp. 525-539. Edited by N. P. Higgins. Washington, DC: American Society for Microbiology.

Chen, C. W. (1996). Complications and implications of linear bacterial chromosomes. Trends Genet 12, 192-196.

Chen, C. W. (2007). Streptomyces linear plasmids: replication and telomeres. In Microbial Linear Plasmids, pp. 33-61. Edited by F. Meinhardt \& R. Klassen. Berlin \& Heidelberg: Springer-Verlag.

Chen, C. W., Yu, T.-W., Lin, Y. S., Kieser, H. M. \& Hopwood, D. A. (1993). The conjugative plasmid SLP2 of Streptomyces lividans is a 50 kb linear molecule. Mol Microbiol 7, 925-932.

Chen, C. W., Huang, C.-H., Lee, H.-H., Tsai, H.-H. \& Kirby, R. (2002). Once the circle has been broken: dynamics and evolution of Streptomyces chromosomes. Trends Genet 18, 522-529.

Clewell, D. B. (1993). Bacterial Conjugation. New York: Plenum Press. Denapaite, D. \& Cullum, J. (1998). Chromosome end of Streptomyces lividans 66 is necessary for the maintenance of the linear plasmid SLP2. In Society for General Microbiology 141st Ordinary Meeting, p. 47. University of East Anglia, Norwich, UK. 
Ducote, M. J., Prakash, S. \& Pettis, G. S. (2000). Minimal and contributing sequence determinants of the cis-acting locus of transfer $(c l t)$ of streptomycete plasmid pIJ101 occur within an intrinsically curved plasmid region. J Bacteriol 182, 6834-6841.

Grohmann, E., Muth, G. \& Espinosa, M. (2003). Conjugative plasmid transfer in Gram-positive bacteria. Microbiol Mol Biol Rev 67, 277301.

Hanafusa, T. \& Kinashi, H. (1992). The structure of an integrated copy of the giant linear plasmid SCP1 in the chromosome of Streptomyces coelicolor 2612. Mol Gen Genet 231, 363-368.

Hopwood, D. A. \& Kieser, T. (1993). Conjugative plasmids of Streptomyces. In Bacterial Conjugation, pp. 293-311. Edited by D. B. Clewell. New York: Plenum Press.

Hopwood, D. A. \& Sermonti, G. (1963). The genetics of Streptomyces coelicolor. Adv Genet 11, 273-342.

Hopwood, D. A., Harold, R. J., Vivian, A. \& Ferguson, H. M. (1969). A new kind of fertility variant in Streptomyces coelicolor. Genetics 62, 461-477.

Hopwood, D. A., Kieser, T., Wright, H. M. \& Bibb, M. J. (1983). Plasmids, recombination and chromosome mapping in Streptomyces lividans 66. J Gen Microbiol 129, 2257-2269.

Hopwood, D. A., Lydiate, D. J., Malpartida, F. \& Wright, H. M. (1984). Conjugative sex plasmids of Streptomyces. In Plasmids in Bacteria, pp. 615-634. Edited by D. Helinski, S. Cohen \& D. Clewell. New York: Plenum.

Hsu, C. C. \& Chen, C. W. (2010). Linear plasmid SLP2 is maintained by partitioning, intrahyphal spread, and conjugal transfer in Streptomyces. J Bacteriol 192, 307-315.

Hsueh, K.-W. (2009). Identification of a cis-acting element on Streptomyces linear plasmid SLP2 for conjugal transfer. MSc thesis, Department of Biotechnology, National Taipei University of Technology.

Huang, C.-H., Lin, Y.-S., Yang, Y.-L., Huang, S. W. \& Chen, C. W. (1998). The telomeres of Streptomyces chromosomes contain conserved palindromic sequences with potential to form complex secondary structures. Mol Microbiol 28, 905-916.

Huang, C. H., Chen, C. Y., Tsai, H. H., Chen, C., Lin, Y. S. \& Chen, C. W. (2003). Linear plasmid SLP2 of Streptomyces lividans is a composite replicon. Mol Microbiol 47, 1563-1576.

Kataoka, M., Kiyose, Y. M., Michisuji, Y., Horiguchi, T., Seki, T. \& Yoshida, T. (1994). Complete nucleotide sequence of the Streptomyces nigrifaciens plasmid, pSN22: genetic organization and correlation with genetic properties. Plasmid 32, 55-69.

Kieser, T., Hopwood, D. A., Wright, H. M. \& Thompson, C. J. (1982). pIJ101, a multi-copy broad host-range Streptomyces plasmid: functional analysis and development of DNA cloning vectors. Mol Gen Genet 185, 223-238.

Kieser, T., Bibb, M., Buttner, M. J., Chater, K. F. \& Hopwood, D. A. (2000). Practical Streptomyces Genetics. Norwich: The John Innes Foundation.

Kinashi, H., Shimaji, M. \& Sakai, A. (1987). Giant linear plasmids in Streptomyces which code for antibiotic biosynthesis genes. Nature 328, 454-456.

Kinashi, H., Shimaji-Murayama, M. \& Hanafusa, T. (1992). Integration of SCP1, a giant linear plasmid, into the Streptomyces coelicolor chromosome. Gene 115, 35-41.

Kirby, R. \& Chen, C. W. (2011). Genome architecture. In Streptomyces: Molecular Biology and Biotechnology, pp. 5-26. Edited by P. Dyson. Norfolk, UK: Caister Academic Press.

Lai, C.-H. (2010). Function of the nuclear localization signals of Streptomyces terminal proteins in plants. MSc thesis, Department of
Life Sciences and Institute of Genome Sciences, National Yang-Ming University.

Levene, S. D. \& Zimm, B. H. (1987). Separations of open-circular DNA using pulsed-field electrophoresis. Proc Natl Acad Sci U S A 84, 4054-4057.

Lin, Y.-L. (1998). Involvement of the terminal sequence of the Streptomyces chromosome in the maintenance of linear plasmids. MSc thesis, Institute of Genetics, National Yang-Ming University.

Lin, Y.-S. \& Chen, C. W. (1997). Instability of artificially circularized chromosomes of Streptomyces lividans. Mol Microbiol 26, 709-719.

Lin, Y.-S., Kieser, H. M., Hopwood, D. A. \& Chen, C. W. (1993). The chromosomal DNA of Streptomyces lividans 66 is linear. Mol Microbiol 10, 923-933.

Liu, H., Naismith, J. H. \& Hay, R. T. (2003). Adenovirus DNA replication. Curr Top Microbiol Immunol 272, 131-164.

Massey, T. H., Mercogliano, C. P., Yates, J., Sherratt, D. J. \& Löwe, J. (2006). Double-stranded DNA translocation: structure and mechanism of hexameric FtsK. Mol Cell 23, 457-469.

Meijer, W. J., Horcajadas, J. A. \& Salas, M. (2001). $\phi 29$ family of phages. Microbiol Mol Biol Rev 65, 261-287.

Pease, P. J., Levy, O., Cost, G. J., Gore, J., Ptacin, J. L., Sherratt, D., Bustamante, C. \& Cozzarelli, N. R. (2005). Sequence-directed DNA translocation by purified FtsK. Science 307, 586-590.

Pettis, G. S. \& Cohen, S. N. (1994). Transfer of the plJ101 plasmid in Streptomyces lividans requires a cis-acting function dispensable for chromosomal gene transfer. Mol Microbiol 13, 955-964.

Pettis, G. S. \& Prakash, S. (1999). Complementation of conjugation functions of Streptomyces lividans plasmid pIJ101 by the related Streptomyces plasmid pSB24.2. J Bacteriol 181, 4680-4685.

Possoz, C., Ribard, C., Gagnat, J., Pernodet, J. L. \& Guérineau, M. (2001). The integrative element pSAM2 from Streptomyces: kinetics and mode of conjugal transfer. Mol Microbiol 42, 159-166.

Qin, Z. \& Cohen, S. N. (1998). Replication at the telomeres of the Streptomyces linear plasmid pSLA2. Mol Microbiol 28, 893-903.

Ray, T., Mills, A. \& Dyson, P. (1995). Tris-dependent oxidative DNA strand scission during electrophoresis. Electrophoresis 16, 888-894.

Redenbach, M., Flett, F., Piendl, W., Glocker, I., Rauland, U., Wafzig, O., Kliem, R., Leblond, P. \& Cullum, J. (1993). The Streptomyces lividans 66 chromosome contains a $1 \mathrm{Mb}$ deletogenic region flanked by two amplifiable regions. Mol Gen Genet 241, 255-262.

Reuther, J., Gekeler, C., Tiffert, Y., Wohlleben, W. \& Muth, G. (2006a). Unique conjugation mechanism in mycelial streptomycetes: a DNAbinding ATPase translocates unprocessed plasmid DNA at the hyphal tip. Mol Microbiol 61, 436-446.

Reuther, J., Wohlleben, W. \& Muth, G. (2006b). Modular architecture of the conjugative plasmid pSVH1 from Streptomyces venezuelae. Plasmid 55, 201-209.

Sambrook, J., MacCallum, P. \& Russell, D. (2001). Molecular Cloning: a Laboratory Manual, 3rd edn. Cold Spring Harbor, NY: Cold Spring Harbor Laboratory.

Servín-González, L. (1996). Identification and properties of a novel clt locus in the Streptomyces phaeochromogenes plasmid pJV1. J Bacteriol 178, 4323-4326.

Sobral, B. W. \& Atherly, A. G. (1989). Pulse time and agarose concentration affect the electrophoretic mobility of cccDNA during PFGE and FIGE. Nucleic Acids Res 17, 7359-7369.

Tiffert, Y., Götz, B., Reuther, J., Wohlleben, W. \& Muth, G. (2007). Conjugative DNA transfer in Streptomyces: SpdB2 involved in the intramycelial spreading of plasmid pSVH1 is an oligomeric integral membrane protein that binds to dsDNA. Microbiology 153, 2976-2983. 
Tinland, B., Koukolíková-Nicola, Z., Hall, M. N. \& Hohn, B. (1992). The T-DNA-linked VirD2 protein contains two distinct functional nuclear localization signals. Proc Natl Acad Sci U S A 89, 7442-7446.

Tsai, J. F.-Y. \& Chen, C. W. (1987). Isolation and characterization of Streptomyces lividans mutants deficient in intraplasmid recombination. Mol Gen Genet 208, 211-218.

Tsai, H.-H., Huang, C.-H., Lin, A. M. \& Chen, C. W. (2008). Terminal proteins of Streptomyces chromosome can target DNA into eukaryotic nuclei. Nucleic Acids Res 36, e62.

Tsai, H.-H., Huang, C.-H., Tessmer, I., Erie, D. A. \& Chen, C. W. (2011). Linear Streptomyces plasmids form superhelical circles through interactions between their terminal proteins. Nucleic Acids Res 39, 2165-2174.

Vivian, A. \& Hopwood, D. A. (1973). Genetic control of fertility in Streptomyces coelicolor A3(2): new kinds of donor strains. J Gen Microbiol 76, 147-162.

Vogelmann, J., Ammelburg, M., Finger, C., Guezguez, J., Linke, D., Flötenmeyer, M., Stierhof, Y.-D., Wohlleben, W. \& Muth, G. (2011a). Conjugal plasmid transfer in Streptomyces resembles bacterial chromosome segregation by FtsK/SpoIIIE. EMBO J 30, 2246-2254.

Vogelmann, J., Wohlleben, W. \& Muth, G. (2011b). Streptomyces conjugative genetic elements. In Streptomyces: Molecular Biology and Biotechnology, pp. 27-42. Edited by P. Dyson. Norfolk, UK: Caister Academic Press.

Wang, J. \& Pettis, G. S. (2010). The tra locus of streptomycete plasmid pIJ101 mediates efficient transfer of a circular but not a linear version of the same replicon. Microbiology 156, 2723-2733.
Wang, S.-J., Chang, H.-M., Lin, Y.-S., Huang, C.-H. \& Chen, C. W. (1999). Streptomyces genomes: circular genetic maps from the linear chromosomes. Microbiology 145, 2209-2220.

Xu, M.-X., Zhu, Y.-M., Shen, M.-J., Jiang, W.-H., Zhao, G.-P. \& Qin, Z.-J. (2006). Characterization of the essential gene components for conjugal transfer of Streptomyces lividans linear plasmid SLP2. Progress in Biochemistry and Biophysics 33, 986-993.

Yamasaki, M., Redenbach, M. \& Kinashi, H. (2001). Integrated structures of the linear plasmid SCP1 in two bidirectional donor strains of Streptomyces coelicolor A3(2). Mol Gen Genet 264, 634-642.

Yang, C.-C., Huang, C.-H., Li, C.-Y., Tsay, Y.-G., Lee, S.-C. \& Chen, C. W. (2002). The terminal proteins of linear Streptomyces chromosomes and plasmids: a novel class of replication priming proteins. $\mathrm{Mol}$ Microbiol 43, 297-305.

Zhong, L., Cheng, Q., Tian, X., Zhao, L. \& Qin, Z. (2010). Characterization of the replication, transfer, and plasmid/lytic phage cycle of the Streptomyces plasmid-phage pZL12. J Bacteriol 192, 3747-3754.

Zhou, X., Deng, Z., Firmin, J. L., Hopwood, D. A. \& Kieser, T. (1988). Site-specific degradation of Streptomyces lividans DNA during electrophoresis in buffers contaminated with ferrous iron. Nucleic Acids Res 16, 4341-4352.

Zhou, X., He, X., Liang, J., Li, A., Xu, T., Kieser, T., Helmann, J. D. \& Deng, Z. (2005). A novel DNA modification by sulphur. Mol Microbiol 57, 1428-1438.

Edited by: P. R. Herron 